\title{
Potential of performance improvement of concentrated solar power plants by optimizing the parabolic trough receiver
}

\author{
(C) The Author(s) 2020. This article is published with open access at link.springer.com and journal.hep.com.cn
}

\begin{abstract}
This paper proposes a comprehensive thermodynamic and economic model to predict and compare the performance of concentrated solar power plants with traditional and novel receivers with different configurations involving operating temperatures and locations. The simulation results reveal that power plants with novel receivers exhibit a superior thermodynamic and economic performance compared with traditional receivers. The annual electricity productions of power plants with novel receivers in Phoenix, Sevilla, and Tuotuohe are 8.5\%, $10.5 \%$, and $14.4 \%$ higher than those with traditional receivers at the outlet temperature of $550^{\circ} \mathrm{C}$. The levelized cost of electricity of power plants with double-selectivecoated receivers can be decreased by $6.9 \%, 8.5 \%$, and $11.6 \%$. In Phoenix, the optimal operating temperature of the power plants is improved from $500^{\circ} \mathrm{C}$ to $560^{\circ} \mathrm{C}$ by employing a novel receiver. Furthermore, the sensitivity analysis of the receiver heat loss, solar absorption, and freeze protection temperature is also conducted to analyze the general rule of influence of the receiver performance on power plants performance. Solar absorption has a positive contribution to annual electricity productions, whereas heat loss and freeze protection temperature have a negative effect on electricity outputs. The results indicate that the novel receiver coupled with low melting temperature molten salt is the best configuration for improving the overall performance of the power plants.
\end{abstract}

Keywords concentrated solar power, parabolic trough receiver, heat loss, solar energy, annual performance

Received Apr. 10, 2020; accepted Jul. 13, 2020; online Nov. 20, 2020

Honglun YANG, Qiliang WANG, Jingyu CAO, Gang PEI ( $($ )

Department of Thermal Science and Energy Engineering, University of Science and Technology of China, Hefei 230026, China

E-mail: peigang@ustc.edu.cn

Jing LI (

School of Engineering and Computer Science, University of Hull, Hull, HU6 7RX, UK

E-mail: Jing.Li@hull.ac.uk

\section{Introduction}

Solar energy is one of the most promising alternative energies that can potentially replace fossil energy to meet the energy consumption in the future [1]. Solar power generation can be classified into two systems, photovoltaic (PV) power systems [2] and concentrated solar power (CSP) systems [3]. At present, the parabolic trough solar power generation system is the high-temperature solar thermal utilization technologies with the most reliable technology, the largest share of the market, and the most economical of the investment [4,5]. Parabolic trough receivers are vital components of parabolic trough CSP plants, which is regarded as the main reason for the high heat loss at high temperature and results in significant collecting efficiency reductions [6]. Typical receivers generally consist of metal absorber tubes, glass envelopes, glass-to-metal seals, and metal bellows. The annular chamber between the steel absorber tube and the glass envelope is evacuated to suppress heat convection and conduction loss [7]. Thus, only radiation heat transfer remains between the absorber and the glass envelope. Solar selective absorbing coatings, which have a high absorption in solar irradiation spectrums but a low thermal emittance in infrared wavelengths, are sputtered on the outer surfaces of steel absorber tubes to suppress infrared radiation loss and enhance solar energy absorption [8]. But the radiation heat loss of the receiver increases exponentially with temperature due to the significant increase of the blackbody emission power and infrared emissivity of the coating. Recently, to pursue a higher thermal to electrical efficiency, molten salt (MS) is used as a heat transfer fluid (HTF) for next generation parabolic trough systems. It may be possible to raise solar field output temperatures up to $550^{\circ} \mathrm{C}$ and the Rankine cycle efficiency of the power block steam turbine to over $40 \%[9,10]$. The major challenges of MS systems are the high heat loss of the solar field at high operating temperatures and the freeze protection energy consumption of the solar field at night or when there is no sunlight, which leads to a low thermal efficiency $[10,11]$. 
Solar field heat loss generally consists of the heat loss of the receivers, the pipelines, and the support frames. Solar field piping and support frame heat losses represent a minuscule portion of the total field thermal losses [12]. Thus, reducing the receiver heat loss is the most effective approach to enhance CSP solar field thermal efficiency.

Developmental studies on advanced receivers with a superior thermal performance are currently being conducted worldwide, beginning with solar selective coatings with high solar absorption and low infrared emittance. Esposito et al. optimized and fabricated several solar selective coatings with an excellent photo-thermal conversion efficiency and thermal stability at high temperatures [13]. Numerous other effective methods were proposed by optimizing the structure of receivers. Wang et al. introduced a novel parabolic trough receiver with a radiation shield on the upper portion of the annular vacuum space, which decreases the receiver heat loss by $19.1 \%$ when the operating temperatures reach $480^{\circ} \mathrm{C}$ [14]. Bellos et al. investigated the utilization of the convergingdiverging absorber tube geometry for operations with thermal oil and determined a $4.25 \%$ mean thermal efficiency enhancement [15]. Bellos and Tzivanidis investigated the star flow insert in a parabolic trough solar collector for thermal efficiency enhancement. These enhancements lead to a decrease in the heat losses up to 14\% [16]. The optimization researches, which employ nanofluids as HTF and adjust receiver structure for enhancing the performance of the receiver, are conducted and concluded by Bellos et al. [17,18]. In system configuration optimization, Yuasa and Hino proposed a MS parabolic trough system with synthetic oil preheating to reduce the anti-freezing solar field area. The heat loss of hybrid systems at night is $31 \%$ lower than that of MS systems. The increase in generated energy of the hybrid systems Abu Dhabi and in Barstow-Daggett are 3.8\% and $3.4 \%$, respectively [19].

Many studies have noted the circumferential nonuniform heat flux distribution over the absorber [20-22] and the spectral distribution of the solar irradiation and thermal emittance [23,24]. Furthermore, the spectral distribution of selective absorbing coatings is closely related to the solar irradiation flux and temperatures. However, traditional parabolic trough receivers coated with only one type of coating on the absorber is unreasonable. Thus, the novel double-selective-coated receiver is proposed in this present papaer. The doubleselective-coated receiver is divided into the primary selective coating region, which corresponds to the high solar irradiation flux surface with concentrated light spots, and the secondary selective coating region, which is an ultra-low emissivity coated area for the decreasing radiation heat loss. The primary selective coating region is a high-solar radiation absorptivity coated area for ensuring against significant receiver heat gain reductions. The thermal performance of the double-selective-coated receiver was analyzed in Ref. [24]. When the temperature of the absorber is $500^{\circ} \mathrm{C}$, the double-coated receiver can reduce the heat loss by $157.8 \mathrm{~W} / \mathrm{m}$, and the percentage of heat loss reduction is $31.1 \%$.

Receiver thermal losses from operation period and MS anti-freezing play the most important roles in the overall performance of CSP plants utilizing MS as HTF. However, the impact of receivers on the overall performance of parabolic trough power systems have not yet been investigated. Therefore, the aim of the present paper is to investigate the potential and the impact of the thermal performance of the receiver on the annual performance of parabolic trough solar power systems with different system configurations. Thermodynamic and economic models are established to predict the performance of CSP plants. The annual electricity production (AEP) and the levelized cost of electricity (LCOE) are adopted to evaluate CSP plants. The thermal balance of the steam Rankine cycle with main steam temperatures ranging from $370^{\circ} \mathrm{C}$ to $540^{\circ} \mathrm{C}$ is calculated and evaluated by the Thermoflow STEAMPRO 19.0 commercial software [25]. Based on the thermodynamic model of the system and the heat loss results of the parabolic trough receiver, the optimizations of the operation parameters of parabolic trough solar power plants with two different receivers are conducted. This process includes a comparison of the different systems in terms of HTFs, operating temperatures, and locations. Furthermore, to explore the potential performance improvements of CSP plants, the CSP plant heat loss process is calculated quantitatively at each thermal conversion process of the power systems. Finally, sensitivity analysis of the receiver heat loss, solar absorption and freeze protection temperature is also conducted to analyze the general rule of influence of the receiver performance on power plants performance.

\section{System mathematical model}

A comprehensive thermodynamic model of the system, including solar field subsystems and a power block subsystem, is established to predict the performance of the solar power plants with different system configuration parameters, including different receivers, HTFs and locations.

\subsection{Solar field subsystem}

\subsubsection{Solar energy absorption}

Solar energy absorption process is the key process of solar thermal utilization. In solar field, rows of the parabolic trough collectors track the sun position and concentrate solar incident ray on the receiver, where the solar irradiation is absorbed by solar selective absorbing coating and converted to thermal energy, and then delivered to the 
HTF for power generation cycle. The solar energy absorbed by the receiver depends on many parameters. In this paper, the effect of the cosine loss, optical loss of the collector and receiver, shadow loss, etc., are taken into account in the solar energy absorption process. The solar energy absorbed by the traditional receiver can be expressed as [26]

$\dot{Q}_{\text {absorbed }}=A \cdot \mathrm{DNI} \cdot \cos \theta \cdot \xi_{\mathrm{IAM}} \cdot \eta_{\text {shadow }} \cdot \eta_{\text {end }} \cdot \eta_{\text {collector }} \cdot \eta_{\text {derate }}$,

where $\dot{Q}_{\text {absorbed }}$ is absorbed solar energy, $\mathrm{W} ; A$ is collector area, $\mathrm{m}^{2} ; \eta_{\text {shadow }}$ is row shadow factor; $\eta_{\text {end }}$ is the end loss factor of the receiver; $\theta$ is solar irradiation incident angle, ${ }^{\circ}$; $\xi_{\text {IAM }}$ is incident angle modifier; and $\eta_{\text {collector }}$ and $\eta_{\text {derate }}$ are the optical efficiencies of collector and parabolic trough receiver, respectively. The value and calculation method of the above parameters are presented in Table 1 [27].

Table 1 Parameters of collector and receiver

\begin{tabular}{lc}
\hline Parameters & Value \\
\hline Aperture width/m & 5.77 \\
Length of collection assembly/m & 150 \\
Incident angle modifier & $\cos \theta+0.000884 \theta-0.00005369 \theta^{2}$ \\
Optical efficiency of the collector & 0.8711 \\
Glass envelope outer/inner & $125 / 120$ \\
diameter/mm & \\
Absorber outer/inner diameter/mm & $70 / 66$ \\
Optical efficiency derate of & 0.8698 \\
receiver & \\
\hline
\end{tabular}

The schematic diagrams of the traditional and the double-selective-coated receivers are demonstrated in
Fig. 1. For the double-selective-coated receiver, there is an additional heat gain loss due to the lower solar irradiation absorption of the secondary selective coating section. The total solar energy absorbed by the doubleselective-coated receiver $\dot{Q}_{\text {absorbed }}^{\prime}$ can be calculated by

$$
\dot{Q}_{\text {absorbed }}^{\prime}=\dot{Q}_{\text {absorbed }}-Q_{\text {absorbed,loss }},
$$

where $Q_{\text {absorbed,loss }}$ is the heat gain loss of the doubleselective-coated receiver, $\mathrm{W} / \mathrm{m}$.

\subsubsection{Solar field heat loss}

The heat loss of the solar field is mainly composed of the heat loss of the receiver, HTF pipeline, and support frames. The heat loss of the traditional and double-selective-coated receiver in various operating conditions, involving different ambient temperatures and wind speeds can be obtained based on the spectrum parameters heat transfer model established in previously [14,24]. In this paper, the heat losses of the traditional and double-selective-coated receiver are fitted as equation according to numerical results of the previous heat transfer model based on spectrum parameters.

$$
\begin{aligned}
& \dot{Q}_{\text {loss,receiver }}=0.03642 T_{\mathrm{abs}, \mathrm{o}}+8.21 \times 10^{-9} T_{\mathrm{abs}, \mathrm{o}}^{4}, \\
& \dot{Q}_{\text {loss }, \text { receiver }}^{\prime}=0.00519 T_{\mathrm{abs}, \mathrm{o}}+5.97 \times 10^{-9} T_{\mathrm{abs}, \mathrm{o}}^{4},
\end{aligned}
$$

where $\dot{Q}_{\text {loss,receiver }}$ and $\dot{Q}_{\text {loss,receiver }}^{\prime}$ are the heat loss of the traditional and double-selective-coated receiver, respectively, $\mathrm{W} / \mathrm{m}$; and $T_{\mathrm{abs}, \mathrm{o}}$ is absorber temperature, ${ }^{\circ} \mathrm{C}$.

HTF pipeline thermal losses of the solar field are calculated by [12]

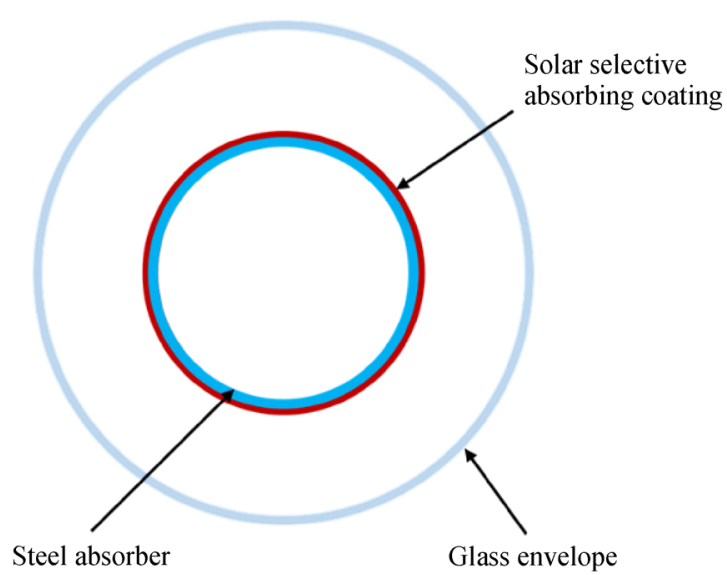

(a)

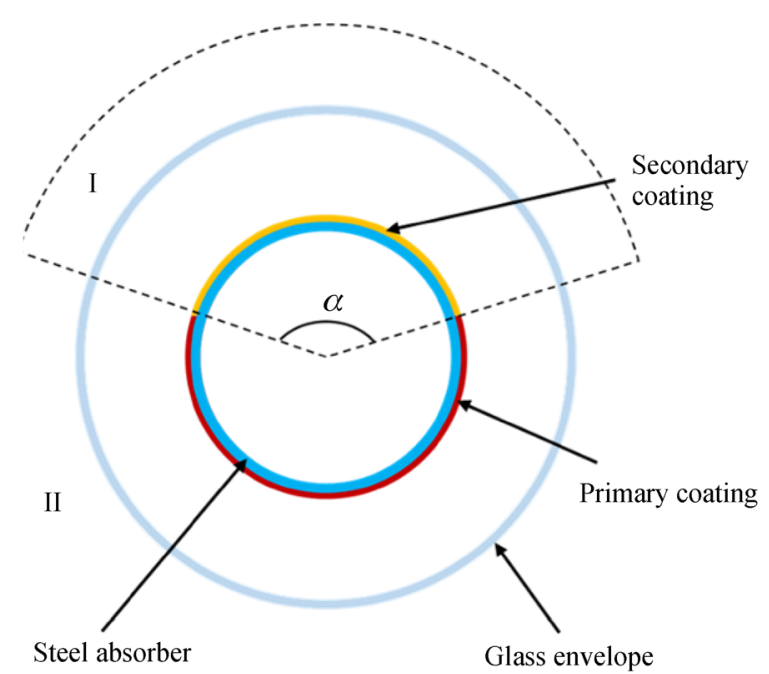

(b)

Fig. 1 Schematic diagrams of traditional and double-selective-coated receivers.

(a) Traditional receiver; (b) double-selective-coated receiver. 
$\dot{q}_{\text {loss,piping }}=0.01693 \Delta T-0.0001683 \Delta T^{2}+6.78 \times 10^{-7} \Delta T^{3}$,

where $\dot{q}_{\text {loss,piping }}$ is the pipeline thermal loss of the solar field, $\mathrm{W} / \mathrm{m}^{2}$; and $\Delta T$ is the difference between average absorber temperature and air temperature, ${ }^{\circ} \mathrm{C}$.

The parabolic trough receivers are placed on the focus line of the collector by a metal collector supporting frame. The frame conduction heat loss from the receiver frame base to frame end $\dot{Q}_{\text {loss,bracket }}$ is given by [28]

$$
\dot{Q}_{\text {loss,bracket }}=\sqrt{h_{\mathrm{b}} P_{\mathrm{b}} k_{\mathrm{b}} A_{\mathrm{cs}, \mathrm{b}}}\left(T_{\text {base }}-T_{\mathrm{a}}\right),
$$

where $h_{\mathrm{b}}$ is the convection heat transfer coefficient between air and the supporting frame, $\mathrm{W} /\left(\mathrm{m}^{2} \cdot \mathrm{K}\right) ; P_{\mathrm{b}}$ is the perimeter of the supporting frame, $\mathrm{m} ; k_{\mathrm{b}}$ is the heat conduction coefficient of the supporting frame, $\mathrm{W} /(\mathrm{m} \cdot \mathrm{K})$; $A_{\mathrm{cs}, \mathrm{b}}$ is the cross-sectional area of the supporting frame, $\mathrm{m}^{2}$; $T_{\text {base }}$ and $T_{\mathrm{a}}$ are the temperature of the frame base and ambient, ${ }^{\circ} \mathrm{C}$.

\subsubsection{Heat transfer model of the absorber}

The HTF heat convection transfer model and heat conduction model of the absorber wall are established to evaluate system thermal deliver performance. The thermophysical properties of nitrate salt and synthetic oil are the function of working temperature and insensitive to the operating pressure. Besides, the pump power variation for solar field HTF cycle under different system configurations is below $0.5 \%$ of the total AEPs and negligible according to solar advisor model (SAM) software data [29]. Thus, the pump power consumption and the pressure drop along the receiver pipeline are ignored.

1) Convection heat transfer between HTF and absorber wall

The convection heat transfer between the HTF and inner absorber wall $\dot{q}_{\text {conv }}$ can be calculated by using the Newtonian cooling formula [30]:

$$
\dot{q}_{\text {conv }}=\pi h_{\mathrm{f}} D_{\mathrm{abs}, \mathrm{i}}\left(T_{\mathrm{abs}, \mathrm{i}}-T_{\mathrm{f}}\right),
$$

where $h_{\mathrm{f}}$ is the convection heat transfer coefficient between the absorber wall and the $\mathrm{HTF}, \mathrm{W} /\left(\mathrm{m}^{2} \cdot \mathrm{K}\right) ; D_{\mathrm{abs}, \mathrm{i}}$ is the inner diameter of the absorber tube, $\mathrm{m} ; T_{\mathrm{abs}, \mathrm{i}}$ and $T_{\mathrm{f}}$ are the temperatures of the inner absorber tube wall and the HTF, ${ }^{\circ} \mathrm{C}$. The calculation of the convection heat transfer coefficient of the interior flow is also presented in Ref. [27].

2) Conduction heat transfer of the receiver wall

The conduction heat transfer of the receiver wall $\dot{q}_{\text {cond }}$ can be calculated according to Fourier's law [30]:

$$
\dot{q}_{\mathrm{cond}}=\frac{2 \pi k\left(T_{\mathrm{abs}, \mathrm{i}}-T_{\mathrm{abs}, \mathrm{o}}\right)}{\ln \left(\frac{D_{\mathrm{abs}, \mathrm{o}}}{D_{\mathrm{abs}, \mathrm{i}}}\right)},
$$

where $k$ is the thermal conductivity of the receiver wall, $\mathrm{W} /(\mathrm{m} \cdot \mathrm{K})$; and $D_{\text {abs,o }}$ is the outer diameter of the absorber tube, $\mathrm{m}$.

\subsection{Power block subsystem model}

The investigated power blocks are the steam Rankine cycles with a single middle reheat. The total installed capacity of the power block subsystem is $100 \mathrm{MW}$ and the thermodynamic of the power block with different inlet main steam temperatures and pressures are analyzed and evaluated by using the STEAMPRO software [25]. The steam turbine cycle efficiency and systems input energy are depicted in Fig. 2. The steam turbine cycle efficiency increases with increasing main steam temperature, which indicates that the synthetic oil systems may suffer from a low thermal-to-electric efficiency because of its inability to operate at temperatures higher than $400^{\circ} \mathrm{C}$. The HTF input energy at design condition decreases with increasing main steam temperature due to the higher cycle efficiency with the same net electricity output at the higher temperature.

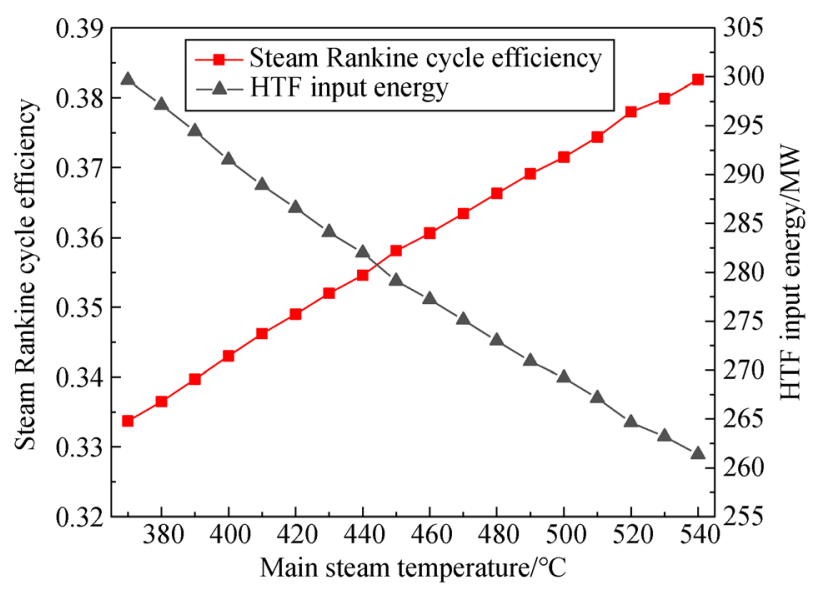

Fig. 2 Steam turbine cycle efficiency and HTF input energy variations with main steam temperatures.

The power block of the CSP plants may often operate under the off-design condition due to the fluctuation of the incident solar irradiation and electric grid demand. The efficiency of the power block subsystem operating under off-design condition can be estimated by the empirical formula [12]:

$$
\begin{aligned}
& \eta_{\text {reduction }}= 0.191-0.409 \times\left(m_{\text {real }} / m_{\text {design }}\right)+0.218 \\
& \times\left(m_{\text {real }} / m_{\text {design }}\right)^{2}, \\
& \eta_{\text {turbine }}=\left(1-\eta_{\text {reduction }}\right) \times \eta_{\text {turbine,design }},
\end{aligned}
$$

where $\eta_{\text {turbine }}$ and $\eta_{\text {turbine,design }}$ are the efficiencies of the power block under actual and rated conditions, respectively; $\eta_{\text {reduction }}$ is the efficiency decrease in partical rated 
condition; and $m_{\text {real }}$ and $m_{\text {design }}$ are the steam mass flow rate under the actual and rated conditions, $\mathrm{kg} / \mathrm{s}$, respectively. This paper assumes that the ratio of the actual mass flow to the rated mass flow is equal to the ratio of the actual HTF input energy to the rated HTF input energy.

Generator efficiency is also a function of the ratio between actual and design electricity power. This efficiency variation ranges from $92.5 \%$ to $98 \%$ approximately. For this paper, the SEGS VI generator efficiency variation $\eta_{\text {generator }}$ has been adopted [31]:

$\eta_{\text {generator }}=0.908+0.258 \times$ load $-0.3 \times$ load $^{2}+0.12 \times$ load $^{3}$,

where load stands for the power load of the power generator. The value of the load is the same as the ratio of the real mass flow rate to the design mass flow rate of the steam.

As aforementioned solar field and power block are established. To couple the solar field subsystem and the power block subsystem, the temperature difference of the steam outlet and HTF inlet of the superheater and reheater is set as $20^{\circ} \mathrm{C}$.

\subsection{Energy balance model}

A two-dimensional energy balance model of the solar field is established based on the above mathematic model, as shown Fig. 3. The HTF loop is divided into ' $n$ ' discrete units along the HTF flow direction. In a discrete volume unit, all temperatures, incident solar irradiation, and properties of the HTF, are regarded as the same and calculated at an average temperature of inlet and outlet temperatures of the discrete unit. Based on the aforementioned assumption and the mathematic model, the steadystate energy balance model of a discrete volume unit is established as

$$
\begin{gathered}
m\left[c_{\mathrm{p}}\left(T_{\mathrm{in}, j}-T_{\mathrm{out}, j}\right)+\frac{1}{2}\left(v_{\mathrm{in}, j}^{2}-v_{\mathrm{out}, j}^{2}\right)\right]+\Delta x \dot{Q}_{\mathrm{absorbed}, j} \\
-\Delta x\left(\dot{Q}_{\text {loss }, \text { receiver }}+\dot{Q}_{\text {loss,bracket }}\right)-\Delta A \dot{q}_{\text {loss }, \text { piping }}=0,
\end{gathered}
$$

where $m$ is the mass flow rate of the $\mathrm{HTF}, \mathrm{kg} / \mathrm{s} ; c_{\mathrm{p}}$ is the specific heat capacity of the $\mathrm{HTF}, \mathrm{J} /(\mathrm{kg} \cdot \mathrm{K}) ; T_{\mathrm{in}, j}$ and $T_{\mathrm{out}, j}$ are the inlet and outlet HTF temperature of the discrete unit, ${ }^{\circ} \mathrm{C} ; v_{\text {in }, j}$ and $v_{\text {out }, j}$ are the flow velocity of the inlet and outlet, $\mathrm{m} / \mathrm{s} ; \Delta x$ is the length of the discrete unit and set as $0.1 \mathrm{~m}$ in this paper; and $\Delta A$ is the solar collector area of the discrete unit, $\mathrm{m}^{2}$. According to Eq. (12), the outlet temperature of the discrete unit can be obtained by giving the inlet temperature and mass flow rate of the HTF. The outlet temperature of the " $j$ " discrete unit is regarded as the inlet temperature of the " $j+1$ " discrete unit. The iteration is performed similarly until a loop cycle of the solar field is finished. Thus, outlet temperatures of the solar field for day and night operation are set as different values for heat collecting and anti-freezing of the MS. Then, the HTF mass flow rate calculation process of the solar field loops is described, as exhibited in Fig. 4. The heat gain of the solar field and electricity production output of the power and

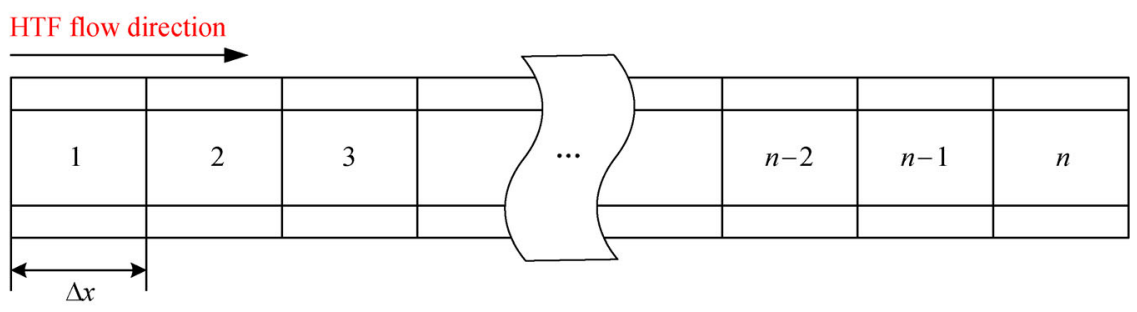

(a)

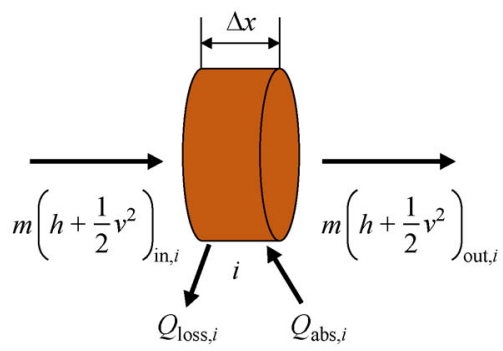

(b)

Fig. 3 Schematic of two-dimensional heat transfer model. (a) Schematic of solar field; (b) energy balance of discrete unit. 


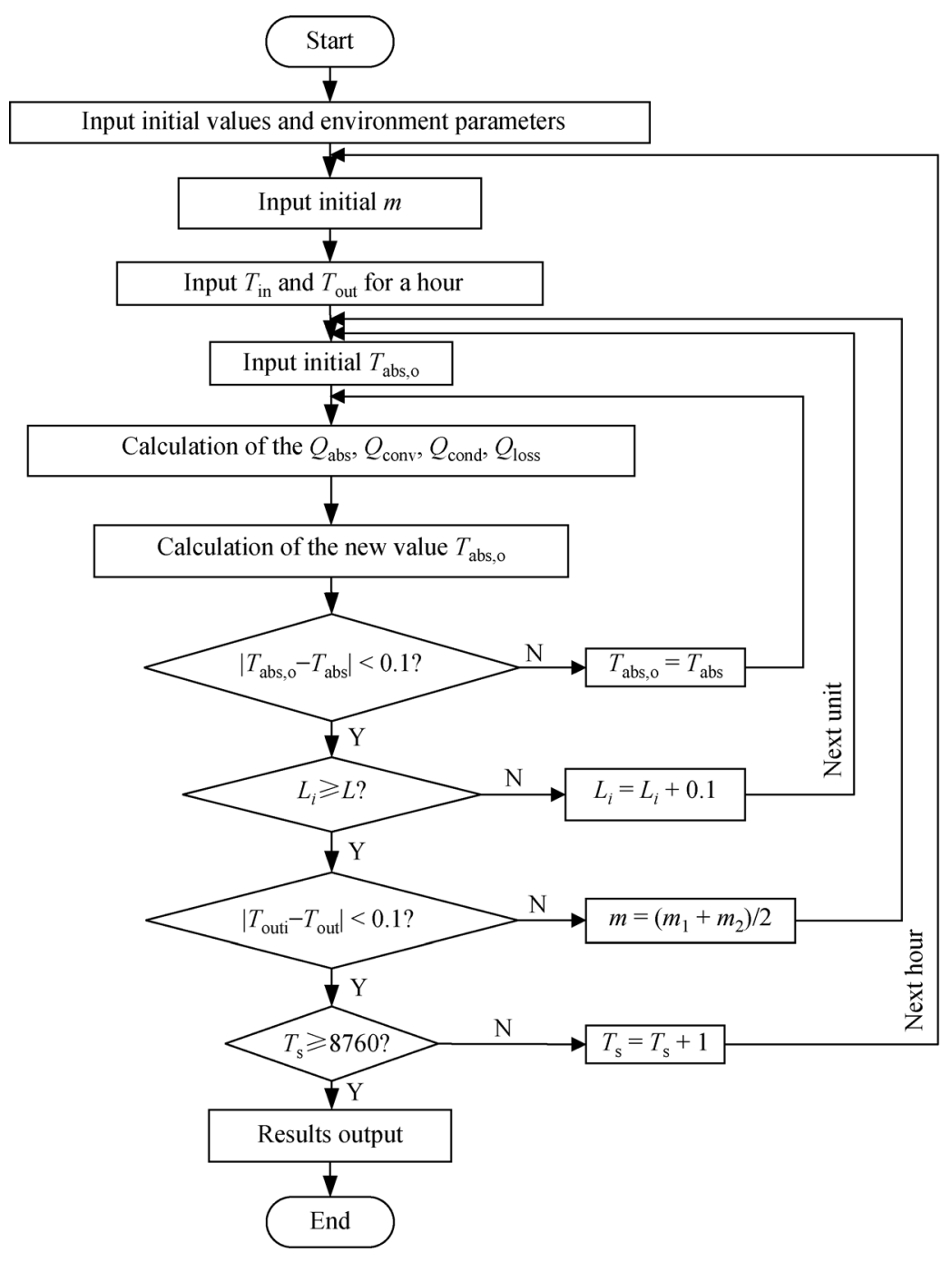

Fig. 4 Flowchart of the computation process of simulation program.

thermal energy consumption for anti-freezing protection of the solar field can be inferred from the HTF mass flow rate and the power block model.

\subsection{Model validation}

The system numerical model is validated. The AEP of the plants using synthetic oil as HTF in Phoenix is validated in SAM software (developed by the National Renewable Energy Laboratory) results. During the validation process, the parameters, including the receiver heat loss, the weather data, the solar field layout, and the power block parameters, are selected as mathematic input parameters. The main CSP plant configuration data are presented in Table 2 . The results of the monthly electricity production of the model agree well with SAM software results with the same operating parameters, including the weather data, the solar field area, and the geometry of the receiver and collector. The AEPs of the developed model and SAM prediction are $378.7 \mathrm{GWh}$ and $381.4 \mathrm{GWh}$, respectively. The annual and monthly electricity productions of those two model have a good agreement as illustrated in Fig. 5. Thus, the error of the current model is acceptable for the annual performance prediction of systems.

\section{Results and discussion}

\subsection{Region selection and design configuration}

In this paper, the performances of CSP plants located in China, Spain, and the US are analyzed. The location and solar irradiation data are tabulated in Table 3 . The weather and location data obtained from the website of software EnergyPlus [32] are used in the current paper. The annual DNI of the Phoenix CSP plant is significantly higher than those of the Sevilla and the Tuotuohe plants. The effective direct normal irradiation $\mathrm{DNI}_{\text {eff }}$ is defined as Eq. (13) for 


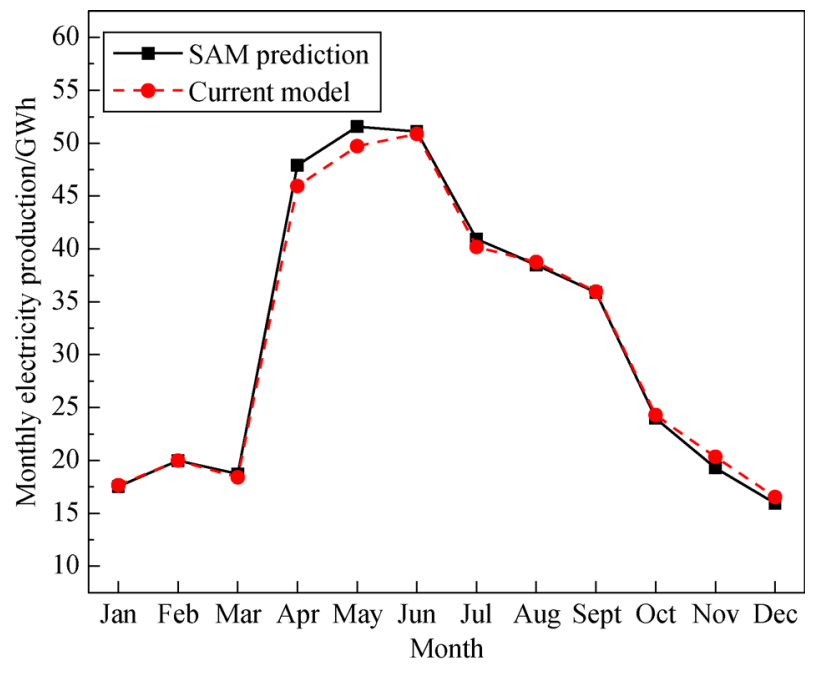

Fig. 5 Comparison of developed model and SAM model.

Table 2 Main plant configuration data

\begin{tabular}{lc}
\hline Parameters & \\
\hline Solar field aperture $/ \mathrm{m}^{2}$ & 882900 \\
Design net turbine output/MW & 100 \\
Solar field HTF & VP-1/Solar salt \\
SCA type & EuroTrough ET150 \\
Number of SCAs per loop & 4 \\
Number of loops & 270 \\
Inlet temperature $/{ }^{\circ} \mathrm{C}$ & 290 \\
Outlet temperature $/{ }^{\circ} \mathrm{C}$ & 390 \\
\hline
\end{tabular}

Table 3 Location and solar irradiation

\begin{tabular}{lccc}
\hline Location & Latitude & Longitude & $\mathrm{DNI} / \mathrm{kWh}$ \\
\hline Phoenix & $33.68^{\circ} \mathrm{N}$ & $112.08^{\circ} \mathrm{W}$ & 2550 \\
Sevilla & $37.42^{\circ} \mathrm{N}$ & $5.90^{\circ} \mathrm{W}$ & 2090 \\
Tuotuohe & $34.22^{\circ} \mathrm{N}$ & $92.43^{\circ} \mathrm{E}$ & 1637 \\
\hline
\end{tabular}

comparing solar irradiation resource levels because of the different plant locations [31].

$$
\mathrm{DNI}_{\text {eff }}=\mathrm{DNI} \times \cos \theta \times \xi_{\mathrm{IAM}} \times \eta_{\text {shadow }} \times \eta_{\text {end }},
$$

where $\mathrm{DNI}_{\text {eff }}$ is the effective DNI of the collector, $\mathrm{W} / \mathrm{m}^{2}$. The effective DNI are presented in Fig. 6, which reveals that the solar irradiation of Tuotuohe is lower than that of Phoenix and Sevilla. The effective annual DNI of Phoenix, Sevilla, and Tuotuohe are 1980, 1625, and $1218 \mathrm{kWh} /$ $\left(\mathrm{m}^{2} \cdot \mathrm{a}\right)$, respectively.

The solar field area is required to deliver sufficient solar energy to drive the power block at the designed turbine gross output under reference weather conditions. In this paper, the solar field area is set as a fixed value to compare the performance of the CSP plants intuitively and designed at the outlet temperature of $390^{\circ} \mathrm{C}$.

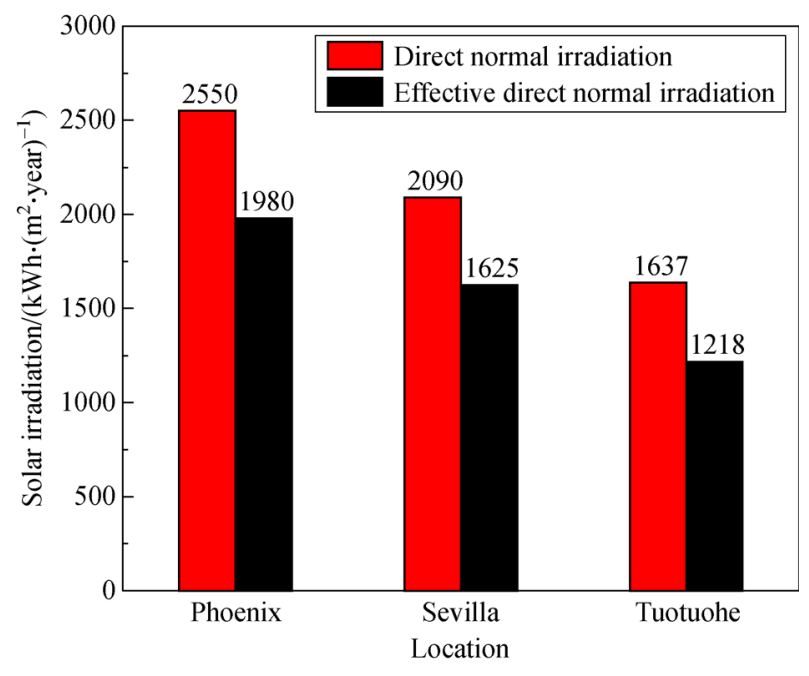

Fig. 6 Solar irradiation of different locations.

$$
\begin{aligned}
& A_{\text {aperture }}=\mathrm{SM} \\
& \times \frac{Q_{\text {input }}}{\mathrm{DNI} \times \eta_{\text {collector }} \times \eta_{\text {derate }}-\dot{Q}_{\text {loss,receiver }}-\dot{q}_{\text {loss,piping }}},
\end{aligned}
$$

where $A_{\text {apeture }}$ is the total aperture of the collector, $\mathrm{m}^{2}$; $Q_{\text {input }}$ is design turbine thermal input, W; and SM is solar multiple. The DNI and solar multiple are set as $750 \mathrm{~W} / \mathrm{m}^{2}$ and 1.8 with an incident angle of $0^{\circ}$ for system design.

\subsection{Energy production process}

The comprehensive performance influence of the utilization of MS as HTFs and double-selective-coated can be concluded as follows [10,33,34]: The high temperature stability of MS allows it to operate in higher temperatures compared to VP-1. Consequently, higher inlet temperatures can be achieved in the power block cycle, which leads to a high steam turbine efficiency. Besides, the average temperature of the MS solar field is high because of high outlet temperatures; thus, the solar field heat loss increases, leading to a low thermal-collecting efficiency of the solar field. Moreover, the freezing temperature of MS $\left(>200^{\circ} \mathrm{C}\right.$ ) is considerably higher than synthetic oil. Therefore, high thermal energy is consumed to protect MS from freezing at night and when there is no sunlight. Furthermore, the heat loss of the double-selective-coated receiver is significantly lower than traditional receivers, which leads to a lower solar field heat loss. Consequently, the collecting efficiency can be increased significantly at operation periods, and the thermal energy utilized for freeze protection decreases when there is sunlight.

The influence of the identified factors on CSP performance is considered separately, that is, the effects are divided into four processes and simulated individually. The simulation parameters of the four processes are 
displayed in Fig. 7. The solar field outlet temperature of parabolic trough power plants utilizing MS as the HTF is set at $550^{\circ} \mathrm{C}$ in this paper [9]. First, CSP plants utilizing synthetic oil as HTFs are simulated, and the solar field outlet temperatures and the steam turbine efficiencies are set at $390^{\circ} \mathrm{C}$ and $33.37 \%$, respectively. Secondly, The value of the steam cycle efficiency at the solar field outlet temperature of $550^{\circ} \mathrm{C}$ and steam turbine inlet temperature of $530^{\circ} \mathrm{C}$ is adopted. The steam turbine efficiency is increased to $38.00 \%$ to analyze the influence of the power cycle efficiency improvement on the AEPs of the plants. Thirdly, the outlet temperatures of the solar fields are set at $550^{\circ} \mathrm{C}$. The anti-freeze protection temperature of solar salt is set as $25^{\circ} \mathrm{C}$ to analysis the improvement of electricity production by enhancing the operation temperature. Finally, the anti-freeze energy consumption effect of MS is considered. The anti-freeze protection temperature is $250^{\circ} \mathrm{C}$. Furthermore, three places are used to analyze the influence of solar irradiation on the AEP.

The influences of the aforementioned effects are presented in Figs. 8 and 9. The CSP plants that use double-selective-coated receivers exhibit a superior thermodynamic and economic performance compared with traditional receivers. The AEP increments of the CSP plants in Phoenix with double-selective-coated receivers utilizing synthetic oil and MS as HTFs are $2.1 \%$ and $8.5 \%$, respectively. Similarly, the increments in Sevilla are $2.3 \%$ and $10.5 \%$ while those in Tuotuohe are $2.7 \%$ and $14.4 \%$. These results indicate that the performance of doubleselective-coated receivers are excellent in areas with a low DNI and a high operating temperature, because heat loss plays an important role in the heat gain of the CSP plants in areas with a low DNI and a high operating temperature.

Figure 8 presents the AEP process of the CSP plants with traditional receivers. The AEPs of the CSP plants utilizing MS as HTFs in all selected regions exhibit negative increases compared to those utilizing synthetic oil. This result can be explained by the high operating temperature heat loss and freeze protection heat loss. The heat losses resulting from high operating temperatures and freeze protection are nearly identical in different locations due to the equal solar field aperture areas and configuration parameters. Energy increments due to high cycle conversion efficiency cannot compensate the energy loss caused by high operating temperatures and freeze protection. The receiver heat loss in MS systems should be paid attention to. An important conclusion reached from the evaluation in this paper is that it is not suitable to build the MS solar
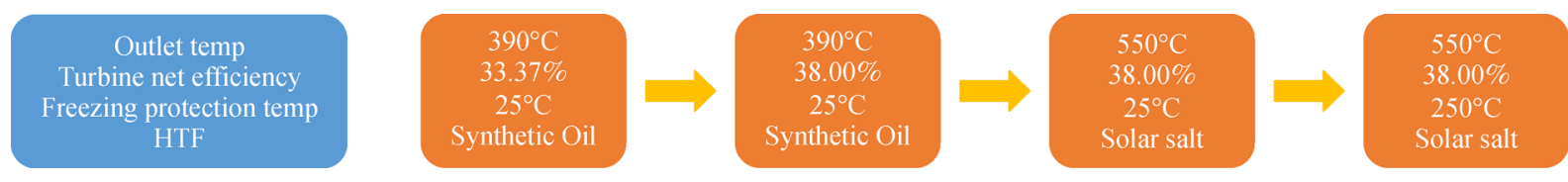

Fig. 7 Simulation process of parabolic trough power plants.

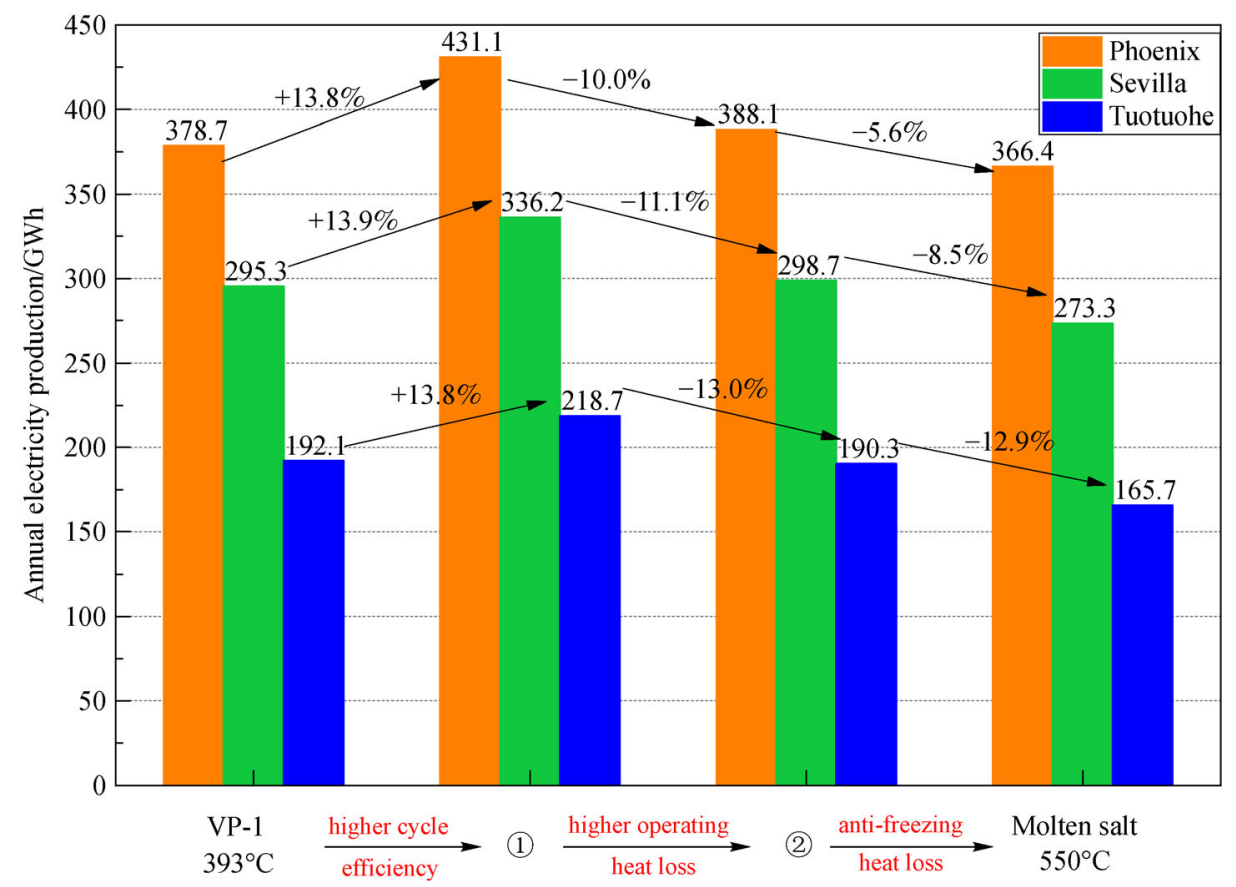

Fig. 8 AEP process of CSP plants with traditional receivers. 


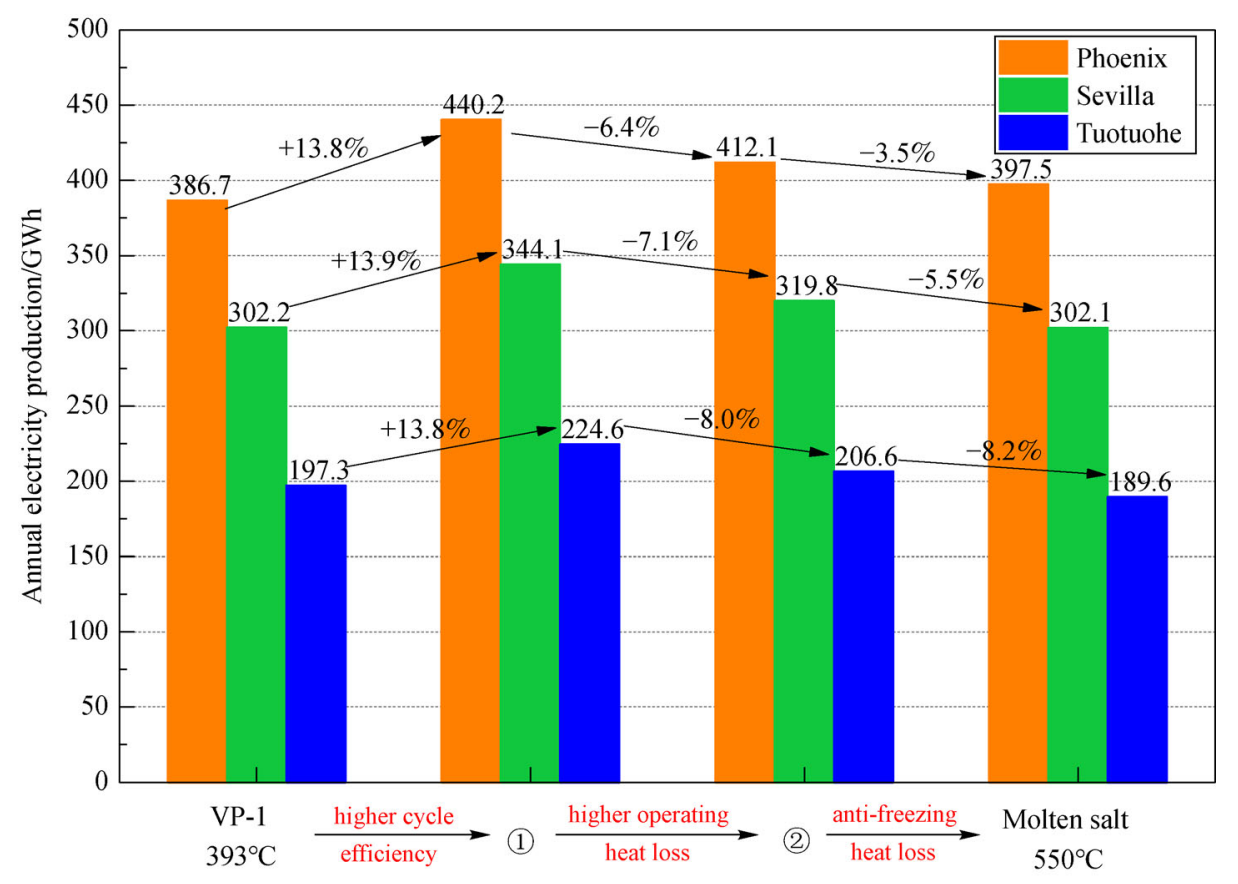

Fig. 9 AEP process of CSP plants with double-selective-coated receivers.

parabolic trough receiver using current receiver technologies and MS thermo physical properties.

Figure 9 presents the AEP process of the CSP plants with double-selective-coated receivers in Phoenix, Sevilla, and Tuotuohe. Unlike the CSP plants with traditional receivers, the AEPs of the CSP plants with doubleselective-coated receivers utilizing MS as HTFs in Phoenix exhibit a positive growth of $2.8 \%$ compared with those utilizing synthetic oil. The reason for this is that the heat loss of double-selective-coated receivers is significantly lower than that of traditional receivers. The heat loss caused by high operating temperatures and freeze protection is reduced. Energy increments due to high cycle conversion efficiency can compensate for the energy loss caused by high operating temperatures and freeze protection in Phoenix. However, the AEPs of the CSPs in Tuotuohe continue to demonstrate a negative increase of $-3.9 \%$ compared with those utilizing synthetic oil due to lower solar irradiation. The heat loss resulting from freeze protection and higher operating temperatures of the CSPs utilizing double-selective-coated receivers is about twothirds of the CSP plants utilizing traditional receivers, which agrees very well with the receiver heat loss reduction result report in Ref. [24]. The heat loss reduction is about $20 \mathrm{GWh}$ by using double-selective-coated receiver in those two processes.

\subsection{Operating temperature optimization}

As mentioned above, the AEPs of the parabolic trough power plants operating at $550^{\circ} \mathrm{C}$ in Sevilla and Tuotuohe do not exhibit a positive increase compared with those operating at $390^{\circ} \mathrm{C}$ even using double-selective-coated receivers. In addition to the heat loss from freeze protection, there is a very important factor due to the higher operating temperature heat loss. Thus, the operating temperatures of parabolic trough power plants should be optimized to acquire maximum AEPs. The AEPs of the plants with traditional and double-selective-coated receivers are simulated at outlet temperatures of $390^{\circ} \mathrm{C}$ to $560^{\circ} \mathrm{C}$ in all locations. Synthetic oil is used as HTF when the outlet temperature of the solar field is below $390^{\circ} \mathrm{C}$, whereas MS is adopted as HTF when the outlet temperature of the solar field exceeds $400^{\circ} \mathrm{C}$. The steam turbine cycle efficiency with main steam temperature ranging from $370^{\circ} \mathrm{C}$ to $540^{\circ} \mathrm{C}$ are presented in Fig. 2.

The AEP variation with solar field outlet temperatures utilizing traditional and double-selective-coated receivers are depicted in Figs. 10 and 11. The effects of different locations and receivers on plant AEPs are analyzed and compared. Double-selective-coated receivers can enhance the AEPs of solar power plants under all conditions. AEPs decrease in solar field outlet temperatures between $390^{\circ} \mathrm{C}$ and $400^{\circ} \mathrm{C}$ for traditional and double-selective-coated receivers. The reason for this is that enormous thermal energy is required to protect the MS from freezing when operating temperatures exceed $400^{\circ} \mathrm{C}$, leading to a lower electricity production at $400^{\circ} \mathrm{C}$. The AEPs of plants utilizing MS increase and then decrease with increasing outlet temperatures. The highest AEP temperatures of the MS plants in Phoenix, Sevilla, and Tuotuohe utilizing traditional receivers are $500^{\circ} \mathrm{C}, 470^{\circ} \mathrm{C}$, and $450^{\circ} \mathrm{C}$, and their corresponding AEPs are 370, 297, and $173 \mathrm{GWh}$, 


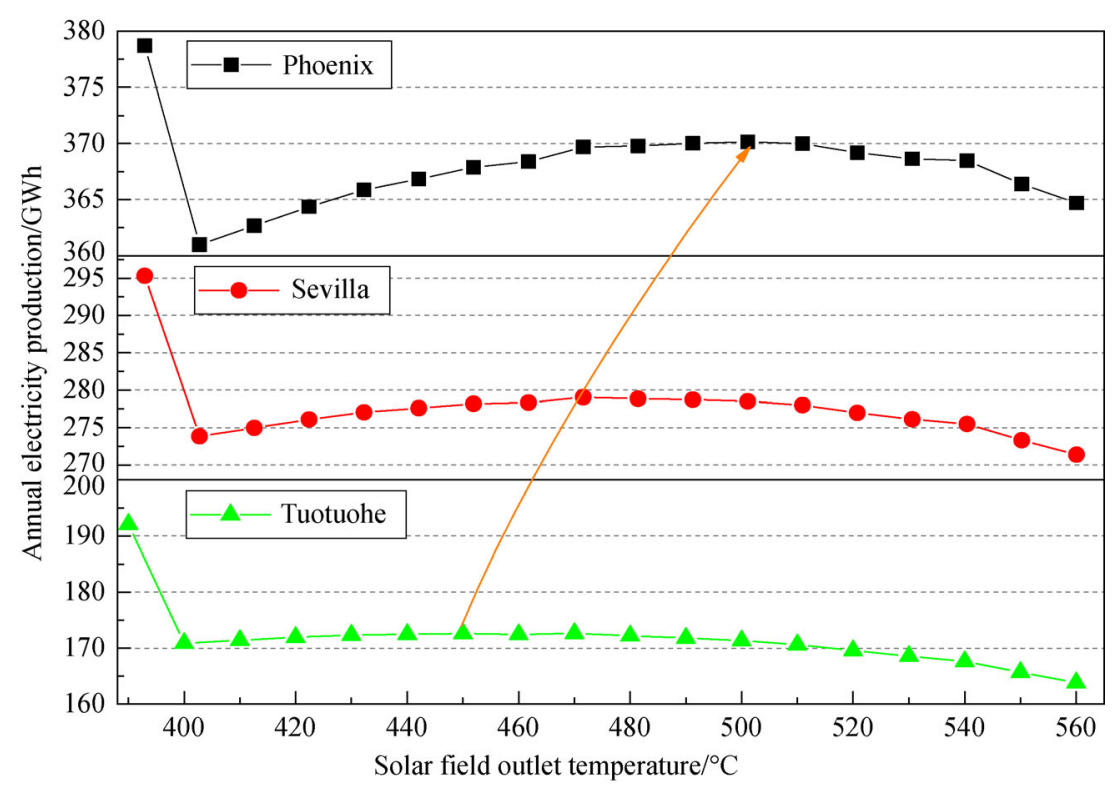

Fig. 10 AEP variation with solar field outlet temperatures utilizing traditional receivers.

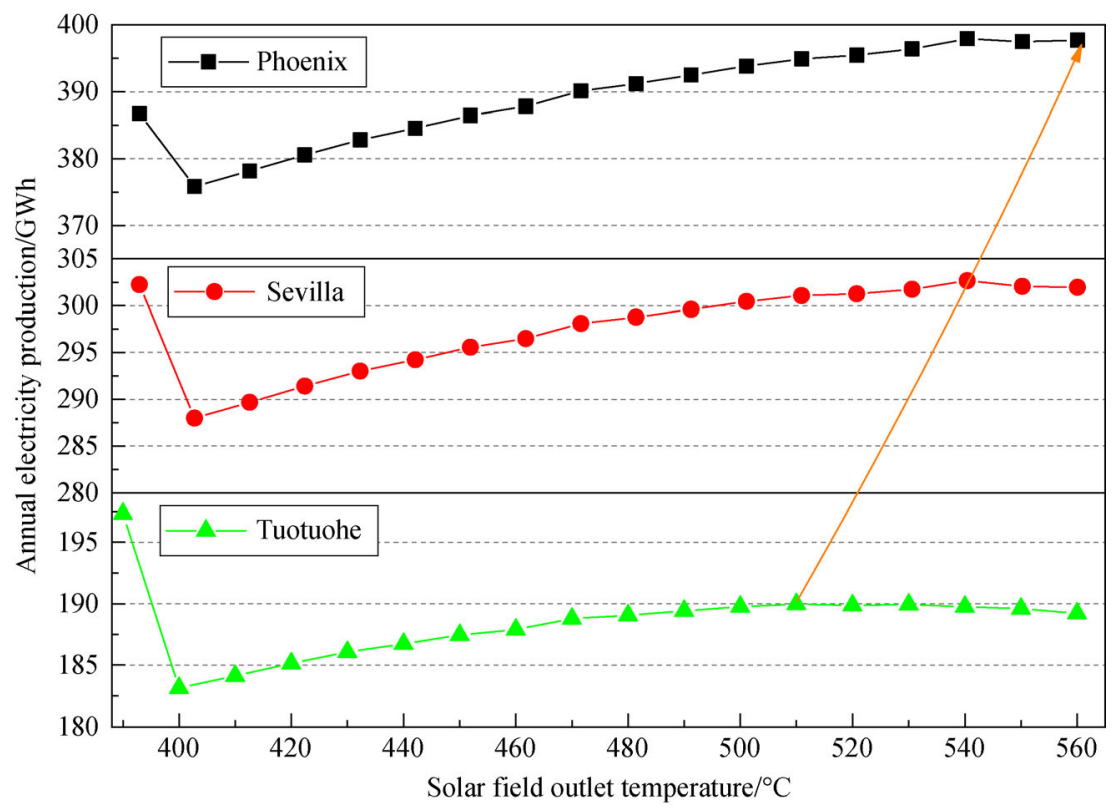

Fig. 11 AEP variation with solar field outlet temperatures utilizing double-selective-coated receivers.

respectively. The highest AEP temperatures of the MS plants in Phoenix, Sevilla, and Tuotuohe utilizing doubleselective-coated receiver are $560^{\circ} \mathrm{C}, 540^{\circ} \mathrm{C}$, and $510^{\circ} \mathrm{C}$, with corresponding AEPs of 398, 303, and $190 \mathrm{GWh}$, respectively. The optimal operating temperatures are enhanced significantly by using the novel double-selective-coated receivers. The AEPs of the MS plants utilizing traditional receivers under all simulation conditions are lower than those of synthetic oil plants in the whole MS operating temperature because of the high receiver heat loss. Unlike the CSP plants with traditional receivers, the optimal AEPs of the MS plants with double-selectivecoated receivers in Phoenix and Sevilla exhibit a positive increase compared with the CSPs using synthetic oil, which indicates that double-selective-coated receivers can potentially expand MS CSP plant application areas and operating temperatures to obtain a high efficiency in regions with a low solar irradiation. 


\subsection{Economic analysis}

The LCOE is the most frequently used index to compare and rank different electricity generation technologies, including CSP, PV, and coal-fired plants. Thus, in this paper, the LCOE is conducted to assess the economic performance of the CSP plants using traditional and double-selective-coated receivers. The LCOE is calculated by using [35]

$$
\mathrm{LCOE}=\frac{\mathrm{CRF} \times C_{\text {invest }}+C_{\mathrm{OM}}}{\mathrm{AEP}},
$$

where CRF is the capital recovery factor of the bank, $C_{\text {invest }}$ is the initial total investment of the plant, and $C_{\mathrm{OM}}$ is the operation and maintenance cost of the solar power plants.

To calculated the LCOE of the power plants, the economic data of the components of the systems is obtained and presented in Table 4 [29]. Parabolic trough receivers typically account for $30 \%$ of the cost of the construction of a solar field [36]. The cost of the doubleselective-coated receiver increases by about $10 \%$ according to factory data. The specific cost of the solar field with double-selective-coated receiver is estimated by the above parameters and listed in Table 4 [29].

Table 4 Economic data of power plants

\begin{tabular}{lc}
\hline Economic data & value \\
\hline Investment & 25 \\
$\quad$ Specific site improvement $/\left(\$ \cdot \mathrm{m}^{-2}\right)$ & $150 / 154.5$ \\
$\quad \begin{array}{l}\text { Specific solar field cost } \\
\text { (traditional/novel receiver }) /\left(\$ \cdot \mathrm{m}^{-2}\right)\end{array}$ & 70 \\
Specific HTF systems $/\left(\$ \cdot \mathrm{m}^{-2}\right)$ & 1150 \\
Specific power block cost $/\left(\$ \cdot \mathrm{kW}^{-1}\right)$ & 120 \\
Balance of plant $/\left(\$ \cdot \mathrm{kW} \mathbf{H}^{-1}\right)$ & 10000 \\
Specific land cost $/\left(\$ \cdot \mathrm{Acre}^{-1}\right)$ & 7 \\
Contingency/\% & \\
O\&M cost & 66 \\
Fixed cost by capacity $/\left(\$ \cdot \mathrm{kW}{ }^{-1} \cdot \mathrm{year}^{-1}\right)$ & 4 \\
Variable cost by generation $/\left(\$ \cdot \mathrm{MWh}^{-1}\right)$ & 1 \\
Financial parameters $/ \%$ & 9.88 \\
Annual insurance cost & 30 \\
CRF/\% & 8 \\
Lifespan of the system $/ \mathrm{year}$ & \\
Bank rate/\% & \\
\hline
\end{tabular}

Table 5 presents the economic performance results. The use of double-selective-coated receivers rather than traditional receivers in parabolic trough CSPs has a tremendous potential in enhancing the economic performance of the CSPs, particularly in high temperatures and low irradiation conditions. The LCOE results of the power plants utilizing synthetic oil and MS are similar to the AEP results. Only the Phoenix MS plants possess an economic strength by utilizing double-selective-coated receiver. The LCOE of MS CSP plants with double-selective-coated receivers in Phoenix, Sevilla, and Tuotuohe can be decreased by $6.9 \%, 8.5 \%$, and $11.6 \%$, respectively.

Table 5 LCOE reduction using double-selective-coated receivers

\begin{tabular}{lcccc}
\hline Location & $\begin{array}{c}\text { Operating } \\
\text { temperature } \\
/{ }^{\circ} \mathrm{C}\end{array}$ & $\begin{array}{c}\text { LCOE with } \\
\text { novel receiver } \\
/\left(\mathrm{cent} \cdot \mathrm{kWh}^{-1}\right)\end{array}$ & $\begin{array}{c}\text { LCOE with } \\
\text { traditional } \\
\text { receiver } \\
/\left(\mathrm{cent} \cdot \mathrm{kWh}^{-1}\right)\end{array}$ & $\begin{array}{c}\text { LCOE } \\
\text { reduction }\end{array}$ \\
\hline Phoenix & $290-390$ & 12.4 & 12.6 & $1.1 \%$ \\
& $290-550$ & 12.1 & 13.0 & $6.9 \%$ \\
Sevilla & $290-390$ & 15.8 & 16.0 & $1.4 \%$ \\
& $290-550$ & 15.8 & 17.3 & $8.5 \%$ \\
Tuotuohe & $290-390$ & 24.0 & 24.4 & $1.7 \%$ \\
& $290-550$ & 25.0 & 28.2 & $11.6 \%$ \\
\hline
\end{tabular}

\subsection{Sensitivity analysis}

Sensitivity analysis of the receiver heat loss, solar absorption, and freeze protection temperature is also conducted to analyze the general rule of influence of the receiver performance on power plants performance.

\subsubsection{Freeze protection temperature}

Nowadays, the freezing point of the commercial MS HTF for power plants is higher than $200^{\circ} \mathrm{C}$, resulting in enormous freeze protection energy consumption. Recently, various low melting point solar salt HTFs have been developed and tested. However, commercial low melting point MS usually suffer from terrible high temperature thermal stability and the operating temperature is limited below $540^{\circ} \mathrm{C}[37,38]$. The novel low melting point solar salt HTFs possess the significant potential to decrease freeze protection energy. The sensitivity of freeze protection is analyzed both for the traditional and doubleselective-coated receiver as shown in Figs. 12 and 13. The empirical equations are still employed to calculate MS properties when the temperature is out of the equation applicable temperature range.

The AEPs of the solar power plants decline with the freeze protection temperature variation increasing from $150^{\circ} \mathrm{C}$ to $270^{\circ} \mathrm{C}$ both for the traditional and doubleselective-coated receiver. When the solar field outlet temperature is $550^{\circ} \mathrm{C}$, there is a significant positive AEP increase of approximately $14 \mathrm{GWh}$ from $375.9 \mathrm{GWh}$ at freeze protection temperature of $150^{\circ} \mathrm{C}$ to $361.5 \mathrm{GWh}$ at freeze protection temperature of $270^{\circ} \mathrm{C}$ for the traditional receiver. The AEP improvement is $10 \mathrm{GWh}$ 


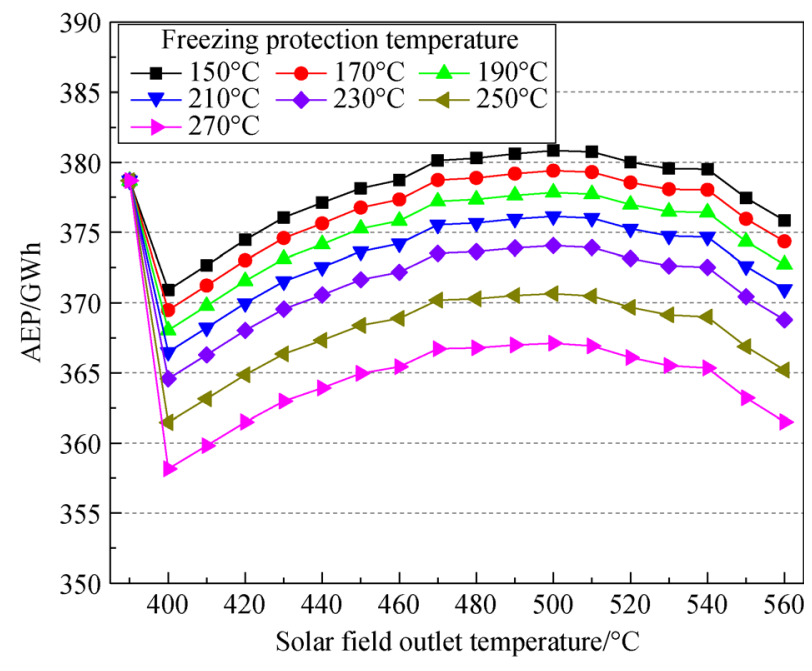

Fig. 12 AEP variation with freeze protection temperatures utilizing traditional receivers.

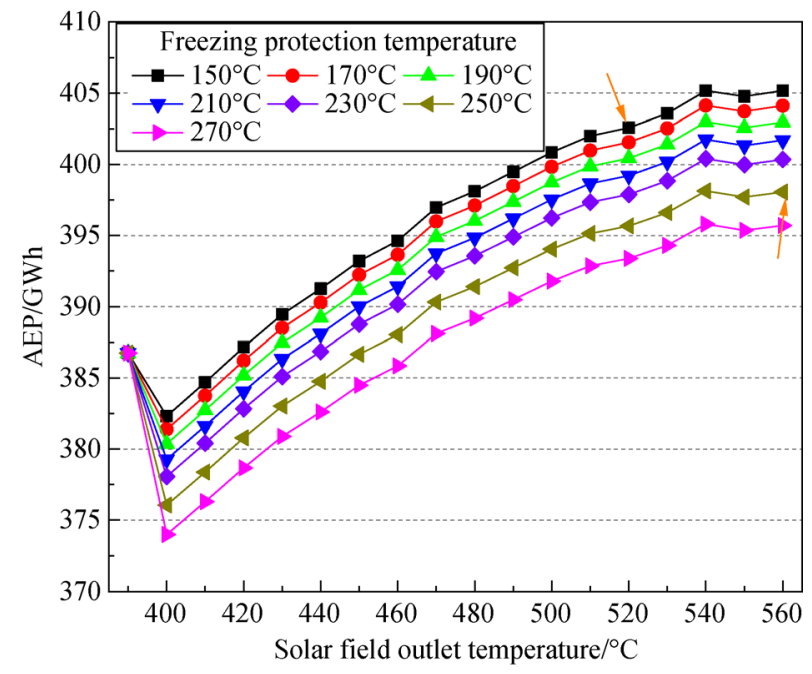

Fig. 13 AEP variation with freeze protection temperatures utilizing double-selective-coated receivers.

for the double-selective-coated receiver. Especially, the highest AEP of the MS power plants with the traditional receiver is slightly higher than the synthetic oil power plant when the freeze protection temperature is below $190^{\circ} \mathrm{C}$. For the double-selective-coated receiver, the highest AEPs of MS power plants are higher than those using synthetic oil as HTF at all freeze protection configuration. The AEP of the power plant with a freeze protection temperature of $150^{\circ} \mathrm{C}$ at a solar field outlet temperature of $520^{\circ} \mathrm{C}$ is 5 GWh higher than that with a freeze protection temperature of $250^{\circ} \mathrm{C}$ at a solar field outlet temperature of $550^{\circ} \mathrm{C}$. It is indicated that the double-selective-coated receiver coupled with low molting MS is the best configuration for improving the overall performance of solar parabolic trough plants.

\subsubsection{Heat loss and solar absorption}

The effects of double-selective-coated receiver heat loss reduction on the performance of the power plants are studied. Generally, the receivers of the solar fields in operation for long periods of time are exposed to damages, such as vacuum loss, broken glass, and hydrogen permeation. Such damages may lead to a sharp increase in receiver heat loss and attenuation in solar absorption. The influences of heat loss increase and solar absorption attenuation have not been discussed in previous studies. Thus, receiver heat loss and solar absorption sensitivity analysis are conducted to explore the effects of the parameters on the overall performance of solar power plants. In this scenario, the solar irradiation and the weather data from Phoenix are used. The fluctuation of the heat loss is sensitive to solar selective coating emissivity and vacuum degree of the receiver. The heat loss of the receiver with 1 torr $\mathrm{H}_{2}$ is more than twice that with a good vacuum while for the different receiver, the absorption rate of the collector tube fluctuates within a small range. Thus, in this paper, the receiver heat loss is adjusted from $-40 \%$ to $40 \%$ based on the traditional receiver to explore the effect of the receiver heat loss with the solar absorption of the receiver remaining unchanged. Then, the receiver heat loss is maintained, and the receiver solar absorption is adjusted from 0.94 to 0.98 .

The AEPs of the solar power plants with outlet temperatures ranging from $390^{\circ} \mathrm{C}$ to $560^{\circ} \mathrm{C}$ decline with the heat loss variation increase from $-40 \%$ to $40 \%$ (Fig. 14). When the solar field outlet temperature is $550^{\circ} \mathrm{C}$, the AEPs experience a dramatic negative decline of approximately $75 \mathrm{GWh}$ from $400.9 \mathrm{GWh}$ at the ratio variation of heat loss of $-40 \%$ to $325.7 \mathrm{GWh}$ at a ratio variation of heat loss of $40 \%$. Moreover, AEP variations by heat loss change are more obvious at high temperatures than at low temperatures. Furthermore, the phenomenon that highest MS plant AEP is higher than those of the synthetic oil plants only occurs at a heat loss ratio variation of $-40 \%$ under the double-selective-coated receiver condition, even in high irradiation areas. The optimal outlet temperature reveals a significant increase from $450^{\circ} \mathrm{C}$ at the heat loss ratio variation of $40 \%$ to $560^{\circ} \mathrm{C}$ and at the heat loss variation of $-40 \%$. These findings imply that the receiver heat loss exerts an important influence on electricity production and optimal operating temperature of CSP plants.

The influence of varying receiver solar absorption on the AEP is depicted in Fig. 15. The solar absorption ranges from 0.94 to 0.98 . The influence of the receiver solar absorption is simpler than that of heat loss. The AEPs of the MS in all solar absorption conditions are lower than those using synthetic oil as HTF. The increased solar absorption range from 0.94 to 0.98 is a positive improvement in AEPs, and the optimal operating temperature does 


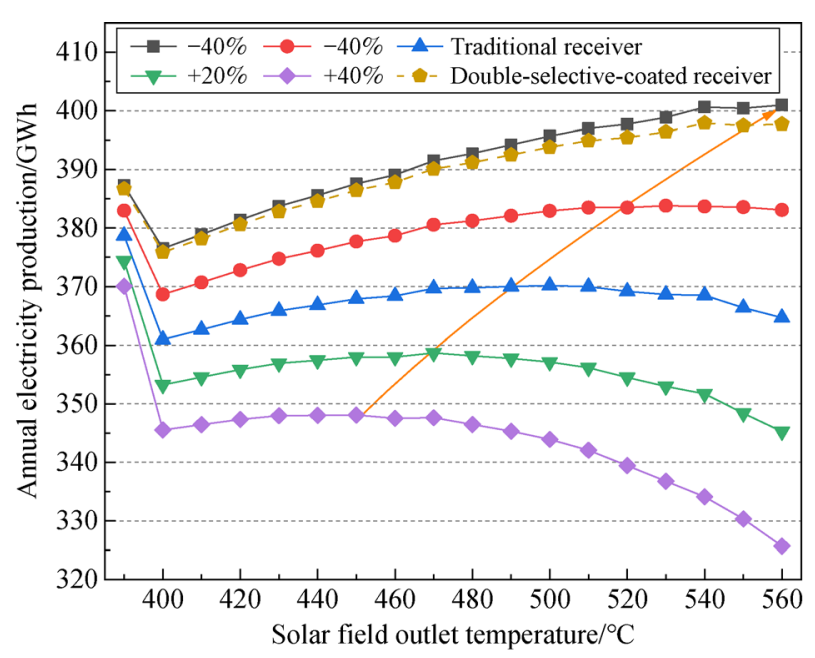

Fig. 14 Influence of varying heat loss on AEP.

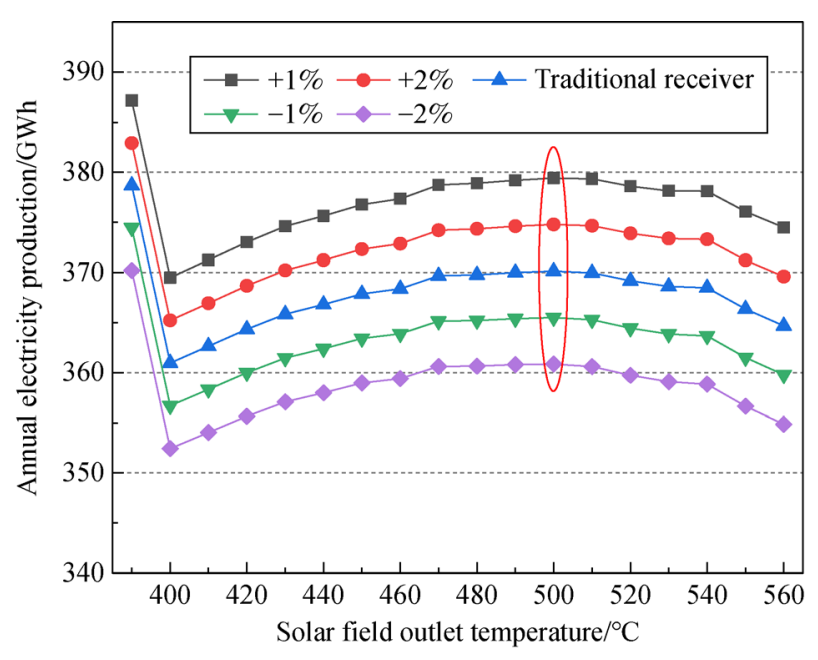

Fig. 15 Influences of varying receiver solar absorption on AEP.

not vary with solar absorption. When the solar field outlet temperature is $550^{\circ} \mathrm{C}$, there is a significant positive AEP increase of approximately $20 \mathrm{GWh}$ from $354.8 \mathrm{GWh}$ at a solar absorption of 0.94 to $374.5 \mathrm{GWh}$ at a solar absorption of 0.98 .

The influence of the heat loss is more complex and obvious than that of the solar absorption, which should be paid more attention to.

\section{Conclusions}

A thermodynamic and economic study is conducted to investigate the effect of utilizing double-selective-coated receivers on parabolic trough solar fields and the influence of utilizing double-selective-coated receivers on the electricity production and the LCOE of CSP plants at different locations under different operating temperature conditions. The following conclusions are summarized according to the numerical simulation results:

The double-selective-coated receiver has the potential for electricity production and cost reduction in parabolic trough systems. The AEPs of the CSP plants with doubleselective-coated receivers in Phoenix, Sevilla, and Tuotuohe are $8.5 \%, 10.5 \%$, and $14.4 \%$ higher than those with traditional receivers at an outlet temperature of $550^{\circ} \mathrm{C}$. The LCOE of the plants with double-selective-coated receivers can be decreased by $6.9 \%, 8.5 \%$, and $11.6 \%$, respectively.

The energy production process analysis suggests that double-selective-coated receiver has a more significant performance advantage at high temperatures. The heat loss reduction is about $20 \mathrm{GWh}$ by using double-selectivecoated receiver at a higher operating temperature and freeze protection process. Furthermore, it is not suitable to build an MS solar parabolic trough receiver using current receiver technologies and MS thermophysical properties.

The optimal operating temperatures are enhanced significantly by using double-selective-coated receivers. The optimal operating temperature of the power plant is increased from $500^{\circ} \mathrm{C}$ to $560^{\circ} \mathrm{C}$ by using double-selectivecoated receiver in Phoenix. The optimal AEP of the MS plants with double-selective-coated receivers in the middle and high radiation region exhibit a positive growth compared with those utilizing synthetic oil. Thus, double-selective-coated receivers can potentially expand MS CSP plant application areas and operating temperatures to achieve a high efficiency in different irradiation regions.

The sensitivity analysis indicates that heat loss and freeze protection temperature exert a negative effect on the performance of plants, while solar energy absorption exerts a positive effect on electricity production. The influence of the heat loss on overall all performance of CSP plant is more complex and obvious than that of the solar absorption. The results indicate that the double-selectivecoated receiver coupled with low molting MS is the best configuration for improving the overall performance of solar parabolic trough plants.

Acknowledgements This work was supported by the National Natural Science Foundation of China (Grant Nos. 51776193 and 5171101721), and the Fundamental Research Funds for the Central Universities (No. WK6030000133).

Open Access This article is licensed under a Creative Commons Attribution 4.0 International License, which permits use, sharing, adaptation, distribution and reproduction in any medium or format, as long as you give appropriate credit to the original author(s) and the source, provide a link to the Creative Commons licence, and indicate if changes were made.

The images or other third party material in this article are included in the article's Creative Commons licence, unless indicated otherwise in a credit line to the material. If material is not included in the article's Creative Commons licence and your intended use is not permitted by statutory regulation or exceeds the permitted use, you will need to obtain permission directly from the copyright holder.

To view a copy of this licence, visit http://creativecommons.org/licenses/ by $/ 4.0 /$. 


\section{Notations}

A

C

D

e

$f_{\text {abs }}$

$h$

k

L

m

$\mathrm{Nu}$

P

Pr

$\dot{q}$

$\dot{Q}$

Re

$T$

$v$

$\eta$

$\theta$

$\Delta x$

$\xi_{\text {IAM }}$

$\lambda$

AEP

CRF

CSP

DNI

HTF

LCOE

MS

SAM

SM

Subscripts

a

abs

b

cond

conv

cs

eff

f

i

invest

o

OM

SCA
Area $/ \mathrm{m}^{2}$

Cost

Diameter/m

Enthalpy $/\left(\mathrm{J} \cdot \mathrm{kg}^{-1}\right)$

Friction factor

Heat transfer coefficient $/\left(\mathrm{W} \cdot \mathrm{m}^{-2} \cdot \mathrm{K}^{-1}\right)$

Conduction coefficient $/\left(\mathrm{W} \cdot \mathrm{m}^{-1} \cdot \mathrm{K}^{-1}\right)$

Length/m

Mass flow rate $/\left(\mathrm{kg} \cdot \mathrm{s}^{-1}\right)$

Nusselt number

Perimeter $/ \mathrm{m}$

Prandtl number

Thermal loss $/\left(\mathrm{W} \cdot \mathrm{m}^{-2}\right)$

Heat transfer rate $/\left(\mathrm{W} \cdot \mathrm{m}^{-1}\right)$

Reynolds number

Temperature $/{ }^{\circ} \mathrm{C}$ or $\mathrm{K}$

Velocity $/\left(\mathrm{m} \cdot \mathrm{s}^{-1}\right)$

Efficiency

Incident angle $/\left({ }^{\circ}\right)$

Discrete unit length/m

Incident angle modifier

Thermal conductivity $/\left(\mathrm{W} \cdot \mathrm{m}^{-1} \cdot \mathrm{K}\right)$

Annual electricity production

Capital recovery factor

Concentrated solar power

Direct normal irradiation

Heat transfer fluid

Levelized cost of electricity

Molten salt

Solar advisor model

Solar multiple

Ambient

Absorber

Frame

Conduction heat transfer

Convection heat transfer

Cross section

Effective

Heat transfer fluid

Inner

Investment

Outer

Operation and maintenance

Solar collector assembly

\section{References}

1. Bellos E, Tzivanidis C. Alternative designs of parabolic trough solar collectors. Progress in Energy and Combustion Science, 2019, 71: 81-117

2. Xuan Q, Li G, Lu Y, Zhao B, Zhao X, Su Y, Ji J, Pei G. Overall detail comparison for a building integrated concentrating photovoltaic/daylighting system. Energy and Buildings, 2019, 199: 415426

3. AlZahrani A A, Dincer I. Energy and exergy analyses of a parabolic trough solar power plant using carbon dioxide power cycle. Energy Conversion and Management, 2018, 158: 476-488

4. Wang F, Cheng Z, Tan J, Yuan Y, Shuai Y, Liu L. Progress in concentrated solar power technology with parabolic trough collector system: a comprehensive review. Renewable \& Sustainable Energy Reviews, 2017, 79: 1314-1328

5. Kannan N, Vakeesan D. Solar energy for future world: a review. Renewable \& Sustainable Energy Reviews, 2016, 62: 1092-1105

6. Olson K D, Talghader J J. Solar selective coating optimization for direct steam generation parabolic trough designs. Solar Energy, 2016, 124: 82-88

7. Lei D, Wang Z, Li J, Li J, Wang Z. Experimental study of glass to metal seals for parabolic trough receivers. Renewable Energy, 2012, 48: 85-91

8. Burlafinger K, Vetter A, Brabec C J. Maximizing concentrated solar power (CSP) plant overall efficiencies by using spectral selective absorbers at optimal operation temperatures. Solar Energy, 2015, 120: $428-438$

9. Maccari A, Bissi D, Casubolo G, Guerrini F, Lucatello L, Luna G, Rivaben A, Savoldi E, Tamano S, Zuanella M. Archimede solar energy molten salt parabolic trough demo plant: a step ahead towards the new frontiers of CSP. Energy Procedia, 2015, 69: 16431651

10. Kearney D, Herrmann U, Nava P, Kelly B. Assessment of a molten salt heat transfer fluid in a parabolic trough solar field. Journal of Solar Energy Engineering, 2002, 125: 293-299

11. Llorente García I, Álvarez J L, Blanco D. Performance model for parabolic trough solar thermal power plants with thermal storage: comparison to operating plant data. Solar Energy, 2011, 85(10): 2443-2460

12. Patnode A M. Simulation and performance evaluation of parabolic trough solar power plants. Dissertation for the Master's Degree. Madison: University of Wisconsin-Madison, 2006

13. Esposito S, D'Angelo A, Antonaia A, Castaldo A, Ferrara M, Addonizio M L, Guglielmo A. Optimization procedure and fabrication of highly efficient and thermally stable solar coating for receiver operating at high temperature. Solar Energy Materials and Solar Cells, 2016, 157: 429-437

14. Wang Q, Li J, Yang H, Su K, Hu M, Pei G. Performance analysis on a high-temperature solar evacuated receiver with an inner radiation shield. Energy, 2017, 139: 447-458

15. Bellos E, Tzivanidis C, Antonopoulos K A, Gkinis G. Thermal enhancement of solar parabolic trough collectors by using nanofluids and converging-diverging absorber tube. Renewable Energy, 2016, 94: 213-222

16. Bellos E, Tzivanidis C. Investigation of a star flow insert in a 
parabolic trough solar collector. Applied Energy, 2018, 224: 86102

17. Bellos E, Tzivanidis C. A review of concentrating solar thermal collectors with and without nanofluids. Journal of Thermal Analysis and Calorimetry, 2019, 135(1): 763-786

18. Bellos E, Tzivanidis C, Tsimpoukis D. Enhancing the performance of parabolic trough collectors using nanofluids and turbulators. Renewable \& Sustainable Energy Reviews, 2018, 91: 358-375

19. Yuasa M, Hino K. Molten salt parabolic trough system with synthetic oil preheating. In: AIP Conference Proceeding. Maryland: AIP Publishing LLC, 2017, 020018

20. Cheng Z D, He Y L, Xiao J, Tao Y B, Xu R J. Three-dimensional numerical study of heat transfer characteristics in the receiver tube of parabolic trough solar collector. International Communications in Heat and Mass Transfer, 2010, 37(7): 782-787

21. Daly J C. Solar concentrator flux distributions using backward ray tracing. Applied Optics, 1979, 18(15): 2696-2699

22. Grena R. Optical simulation of a parabolic solar trough collector. International Journal of Sustainable Energy, 2010, 29(1): 19-36

23. Cao F, McEnaney K, Chen G, Ren Z. A review of cermet-based spectrally selective solar absorbers. Energy \& Environmental Science, 2014, 7(5): 1615-1627

24. Yang H, Wang Q, Huang X, Li J, Pei G. Performance study and comparative analysis of traditional and double-selective-coated parabolic trough receivers. Energy, 2018, 145: 206-216

25. Thermoflow STEAMPRO 19.0 simulation software. Jacksonville: Thermoflow Inc, 2017

26. Forristall R. Heat transfer analysis and modeling of a parabolic trough solar receiver implemented in engineering equation solver. National Renewable Energy Laboratory, Golden, CO, USA, 2003

27. Yang H, Wang Q, Huang Y, Gao G, Feng J, Li J, Pei G. Novel parabolic trough power system integrating direct steam generation and molten salt systems: preliminary thermodynamic study. Energy Conversion and Management, 2019, 195: 909-926

28. Padilla R V, Demirkaya G, Goswami D Y, Stefanakos E, Rahman M M. Heat transfer analysis of parabolic trough solar receiver. Applied
Energy, 2011, 88(12): 5097-5110

29. System Advisor Model (SAM). Version 2019. National Renewable Energy Laboratory, 2019

30. Bergman $\mathrm{T}$ L, Lavine A S, Incropera F P, DeWittk D P. Fundamentals of Heat and Mass Transfer. 7th ed. Hoboken: John Wiley \& Sons, 2011

31. Liu Q, Bai Z, Sun J, Yan Y, Gao Z, Jin H. Thermodynamics investigation of a solar power system integrated oil and molten salt as heat transfer fluids. Applied Thermal Engineering, 2016, 93: 967-977

32. Energy Plus energy simulation software: weather data. 2020-04-05, available at website of Energyplus

33. Kearney D, Kelly B, Herrmann U, Cable R, Pacheco J, Mahoney R, Price H, Blake D, Nava P, Potrovitza N. Engineering aspects of a molten salt heat transfer fluid in a trough solar field. Energy, 2004, 29(5-6): 861-870

34. Kearney D, Herrmann U, Nava P, Kelly B, Mahoney R, Pacheco J, Cable R, Potrovitza N, Blake D, Price H. Evaluation of a molten salt heat transfer fluid in a parabolic trough solar field. In: ASME Solar 2002: International Solar Energy Conference. Reno: American Society of Mechanical Engineers Digital Collection, 2002, 293299

35. Montes M J, Abánades A, Martínez-Val J M, Valdés M. Solar multiple optimization for a solar-only thermal power plant, using oil as heat transfer fluid in the parabolic trough collectors. Solar Energy, 2009, 83(12): 2165-2176

36. Wu Z, Li S, Yuan G, Lei D, Wang Z. Three-dimensional numerical study of heat transfer characteristics of parabolic trough receiver. Applied Energy, 2014, 113: 902-911

37. Wu Y T, Li Y, Ren N, Zhi R P, Ma C F. Experimental study on the thermal stability of a new molten salt with low melting point for thermal energy storage applications. Solar Energy Materials and Solar Cells, 2018, 176: 181-189

38. Nunes V M B, Queirós C S, Lourenço M J V, Santos F J V, Nieto de Castro C A. Molten salts as engineering fluids - a review. Applied Energy, 2016, 183: 603-611 